\title{
ENTREVISTA: WILLIAM RODRIGUES
}

\section{COMEÇAMOS DA ESTACA ZERO}

entrevistado por Regina Melo edição e revisão George Rebêlo

\begin{abstract}
Mineiro de São João Del Rei, onde nasceu em 1928, William Antônio Rodrigues resume a própria história do INPA, aonde chegou ainda nos primórdios para organizar o setor de Botânica. Hoje aposentado, vive em Curitiba (PR), mas achou tempo para recordar em suas memórias muito desta história que, para muitos, ainda é desconhecida. Ainda na ativa, publicou até agora mais de 160 trabalhos, incluindo 2 livros, 34 capítulos de livros, 75 artigos em revistas científicas nacionais e estrangeiras e cerca de 60 comunicações publicadas em anais de eventos científicos nacionais e internacionais. Propôs quarenta plantas como novas entidades, descobriu um gênero novo de Euforbiácea (Micrandropsis), pertencente a família das seringueiras. Dentre inúmeras outras espécies coletadas por ele e descritas por outros especialistas, um gênero novo da família das Lauráceas, Williamodendron, gênero próximo da itaúbas (Mezilaurus), foi descrito pelo botânico alemão Klaus Kubitzki em sua homenagem. A espécie tipo é uma portentosa árvore, de lindo aspecto, só conhecida até agora nas florestas de terra firme ao longo da estrada ManausItacoatiara, além do km 125. Uma justa homenagem a um cientista da sua importância.
\end{abstract}

\section{A FORMAÇÃO ACADÊMICA}

Em 1953 bacharelei-me em História Natural pela Faculdade de Filosofia, Ciências e Letras da Universidade do Distrito Federal, hoje Universidade Estadual do Rio de Janeiro (UERJ). Em 1956 licenciei-me em História Natural pela mesma faculdade. Em 1954 conclui o curso de especialização em Botânica Médica pelo Instituto Oswaldo Cruz. Em 1951 especializei-me em Técnica de Laboratório pela Universidade Rural do Rio de Janeiro. Em 1970 assumi a cadeira 38 (patrono Barbosa Rodrigues) na Academia Amazonense de Letras, com o discurso de posse intitulado "Na poltrona de Barbosa Rodrigues", tendo sido saudado na ocasião pelo saudoso acadêmico Cosme Ferreira Filho com o discurso "William Rodrigues, a botância e a Amazônia". Em 1977, doutorei-me em Ciências pela Universidade Estadual de Campinas UNICAMP com a tese "Revisão taxonômica das espécies de Virola Aublet (Myristicaceae) do Brasil". O pós-doutorado foi feito entre 1982-1983, no Jardim Botânico de Nova Iorque, Estados Unidos, com o estudo taxonômico das espécies neotropicais da família botânica Myristicaceae, graças a uma bolsa concedida pela John Simon Guggenheim Memorial Foundation. Antes de ingressar no INPA, fiz vários cursos de especialização em Botânica Agrícola, no Rio de Janeiro, entre 1952-1953, em particular na Escola de Horticultura Wenceslao Bello. Por recomendação do Dr. Olympio da Fonseca, primeiro Diretor do INPA, fundador do curso de Botânica Médica do Instituto Oswaldo Cruz e meu ex-professor de Biologia Geral, estagiei na Divisão de Botânica do Museu Nacional do Rio de Janeiro, entre agosto-outubro de 1954, a título de preparação para iniciar a montagem e organização do setor de Botânica do INPA, em Manaus, juntamente com o farmacêutico Renato José de Siqueira Jaccoud. Entre maionovembro de 1967, estive no Japão, com uma bolsa oferecida pelo Governo Japonês, para participar de um treinamento em grupo sobre Pesquisas Florestais e Produtos Florestais. Durante todo o ano de 1971, a John Simon Guggenheim Memorial Foundation concedeu-me uma bolsa de estudos para consultar os principais herbários mundiais não só nos Estados Unidos como da Europa que detenham coleções amazônicas clássicas colhidas pelos primeiros naturalistas, que perlustraram a Amazônia, como Martius, Spruce, Schomburg, Bonpland \& Humboldt, Poeppig, Ule, Malme e muitos outros, cujas coleções encontravam-se depositadas nesses herbários e dificilmente poderiam ser emprestadas. Em 1963, organizei e presidi a XIV Reunião Anual da Sociedade Botânica do Brasil - primeiro evento a se realizar no estado do Amazonas - de cujo encontro resultou a publicação dos anais do evento, dos quais fui editor junto com o Dr. Nelson Maravalhas, químico do INPA. Nessa ocasião, inauguramos simbolicamente, no dia 23 de janeiro, a Reserva Biológica Walter Egler com 750 hectares, localizada na estrada Manaus-Itacoatiara, com a presença do diretor do INPA, Dr, Djalma Batista, e de todos os congressistas.

\section{A ESPECIALIZAÇÃO DE UM BOTÂNICO}

Devo minha formação botânica em especial aos Drs. João Geraldo Kuhlmann e João Murça Pires. Dr. Kuhlmann (emérito botânico, conhecedor profundo da flora brasileira, ex-diretor do Jardim Botânico do Rio de Janeiro, falecido em 1958) foi consultor do INPA juntamente com o Dr. Adolfo Ducke. A ele devo minha introdução na Botânica Sistemática como professor do curso de Botânica Médica no Instituto Oswaldo Cruz, em 
1953, e posteriormente, durante os primeiros anos de minha carreira. Mantive vários contatos pessoais com ele no Rio, em especial, para me ajudar e orientar na identificação das plantas do herbário do INPA. Com muita paciência e espírito de colaboração, não me escondia nada sobre tudo que sabia sobre a flora amazônica. Aprendi muito com ele nessa fase até a sua morte. Publiquei um trabalho em co-autoria com ele sobre algumas novas plantas da flora dos campos de Roraima. Tudo que aprendia com ele, transmitia depois à minha equipe de auxiliares do INPA, inclusive aos auxiliares de campo. Esse contato constante e direto com ele foi de uma valia inestimável, visto que sem a presença no INPA de um outro botânico ou de um herbário de referência e de fácil acesso em Manaus ou próximo, o nosso trabalho de identificação taxonômica das plantas amazônicas tornar-se-ia muito difícil ou quase impossível.

O Dr. João Murça Pires (ex-pesquisador do Instituto Agronômico do Norte - IAN e do Museu Emílio Goeldi, falecido em 21/12/1994) era um excelente conhecedor da flora amazônica, em parte adquirida em convívio direto com o Dr. Adolfo Ducke. Ele foi fundador, entre outros, do herbário do Instituto Agronômico do Norte (IAN), hoje EMBRAPA. Era um grande amigo meu, convivi com ele inúmeras vezes, tanto em Manaus como em Belém. Participei de várias excursões pela Amazônia em companhia dele. Numa das vezes, colhemos em Rondônia uma rara espécie nova de "pinheiro" da família das Podocarpáceas descrita como Decussocarpus piresii J. Silva. Seus vastos conhecimentos sobre flora amazônica me valeram muito. Chegamos a publicar alguns trabalhos juntos.

Outro, que, também, contribuiu em parte para a minha formação como fitossociólogo foi o renomado Prof. André Aubréville, fitogeógrafo, já falecido, na época Diretor do Laboratório de Fanerógamos do Museu Nacional de História Natural, de Paris. Quando esteve no INPA, traçou um programa de trabalhos para o Centro de Pesquisas Florestais. Com parte desse Programa, passei a estudar e fazer levantamentos fitossociológicos de alguns tipos de vegetação amazônica. Eu o acompanhei em quase todas suas excursões pela Amazônia como convidado do Governo Brasileiro. Ajudei-o no campo em seus estudos fitossociológicos, incluindo a região de Manaus, Roraima (campos do Rio Branco), Amapá (Serra do Navio) e Belém. Publiquei em seu importante livro intitulado "Étude écologique des principales formations végétales du Brésil et contribuition a la connaissance des forêts de l'Ämazonie brésilienne" um capítulo dos meus estudos pessoais sobre a fitossociologia das pseudo-caatingas amazônicas e florestas de várzea do rio Negro.

\section{O INGRESSO NO INPA}

Fui admitido no INPA em 21/10/1954, após passar à disposição do CNPq por um ano, por autorização do Ministério da Guerra (hoje do Exército [Defesa]), de onde eu era funcionário de carreira.
A minha primeira viagem para Manaus deu-se em um Constelation da Panair (hoje Varig). Foi uma longa e cansativa viagem noturna, sem escalas, até Belém, e daí direto para o aeroporto de Ponta Pelada, em Manaus. Fiquei hospedado no Hotel Amazonas, o melhor da cidade, na época. Nos primeiros dias de minha estada em terras manauaras, impressionou-me bastante o seu clima com chuvas torrenciais repentinas e passageiras e um calor um tanto ameno para a época. A minha recepção no INPA também foi muito boa. Se bem que o Dr. Jaccoud, a única pessoa com quem eu me dava desde o Rio, estivesse em excursão em Roraima, logo comecei a me relacionar com alguns colegas e formar amigos, a maioria também recémchegados e vindos do Sul (em especial do Rio de Janeiro e São Paulo) e outros do exterior, como o espanhol, Dr Isquierdo, veterinário, e o porto-riquenho, Dr. Justino Ramon, médico e o paulista, veterinário, Dr. Walter, os quais foram excelentes companheiros nessa fase de adaptação em terras longínquas - pela primeira vez, afastado do convívio de meus familiares e amigos, em especial dos meus pais, com quem sempre morei, antes de deixar o Rio. A sede provisória do INPA funcionava num prédio situado na Praça da Saudade. Na parte principal do prédio funcionava o escritório e nos fundos existia uma sala destinada ao herbário da Botânica. Tudo aí era improvisado, enquanto não se dispunha de uma sede própria. Como a energia elétrica na época era praticamente inexistente ou muito escassa na cidade e não dispúnhamos ainda de algum laboratório montado para os nossos trabalhos iniciais, em especial, para secagem das plantas colhidas no campo, as amostras botânicas eram secas em geral à luz solar. A única funcionária encarregada desses serviços era a Maria Helena Bacelar, contratada como auxiliar de laboratório juntamente com dois auxiliares de campo, entre eles o Joaquim Chagas de Almeida, ex-mateiro do Dr. Adolfo Ducke.

Segundo opinião do Dr.Jaccoud, quem realmente foi o verdadeiro fundador do Herbário do INPA foi o Dr. Olympio da Fonseca seguido de nós. O Dr. Jaccoud, foi o primeiro pesquisador contratado pelo INPA (maio ou junho de 1954), chegou a Manaus na manhã de 27/07/ 1954, trazendo consigo um microscópio.

A cidade de Manaus com cerca de 120 mil habitantes, estava passando por uma crise tremenda provocada especialmente pela debacle da borracha. Faltava água, luz e o alimento, em especial, o perecível - como carne, peixe, etc.era muito escasso e disputado, ainda pela madrugada, no único centro de abastecimento da cidade - Mercado Municipal. Edifícios suntuosos como o Teatro Amazonas, o Prédio da Alfândega, o cais flutuante, algumas pontes localizadas na Av. Sete de Setembro e algumas outras obras daquela memorável época áurea estavam lá como testemunho do período do fastígio de Manaus.. Manaus chegou a ser a segunda cidade do país a ter iluminação publica. Tudo isso me impressionou bastante. Embora inteiramente isolada dos grandes centros, podia-se admitir para a época, que Manaus 


\section{ACTA \\ AMAZONICA}

era um oásis perdido na imensidão da floresta amazônica. Seu povo muito hospitaleiro e alegre e sua elite em geral culta e de fino trato, muitos deles educados na Europa, logo me cativaram. Embora na época não existisse mais em Manaus a Universidade de Manaus, a mais antiga do Brasil ${ }^{1}$, funcionavam na capital do Amazonas, em nível superior, apenas a Faculdade de Direito e os curso de Enfermagem e o de Serviço Social. Em nível médio, também se destacavam o Instituto de Educação, que, mantinha, também, curso noturno, o Ginásio Estadual do Amazonas, também com curso noturno, a Escola Técnica e a Escola Agrícola. Quando desembarquei em Manaus, observei, logo, que a cidade era provinciana, sem poluição sonora ou atmosférica de qualquer espécie, muito típica das grandes cidades, como o Rio ou São Paulo, pachorrenta, raros carros circulando pela cidade, relativamente pequena, porém limpa, bem ensolarada, clara e simpática, que se estendia principalmente pelos bairros de Adrianópolis, considerado o mais aristocrático da cidade, São Raimundo, Cachoeirinha, Educandos, Flores e São Jorge. Os lugares mais distantes, usados, em geral, pela população para passeios nos fins de semana, eram formados pela Colônia do Aleixo, Balneário do Parque Dez e da Ponte da Bolívia e a Cachoeira do Tarumã-Mirim. Para se chegar até a cachoeira do Tarumã-Grande só existia uma trilha, que em geral se fazia a pé e para se ir até as praias de Ponta Negro, só se fosse de barco. O comércio adotava a sesta, entre as 12 e 14 horas. Tudo mantinha-se fechado e a cidade morria. Os poucos veículos mais comuns para se alugar na cidade eram os jeeps, que, em geral, ficavam estacionados na esquina da Eduardo Ribeiro com a Sete de Setembro, do lado da Matriz. A princípio, o INPA alugou muitos desses veículos para excursões ou para os serviços administrativos. Os nossos mateiros em seus trabalhos de campo, no início, utilizavam o ônibus e como em geral vestiam um macacão azul igual ao dos doentes do Hospício de Flores comumente eram confundidos com esses doentes mentais, especialmente quando estavam herborizando no campo. A vida dos pesquisadores casados, que tinham vindo com seus familiares de outras cidades do Sul para morar em Manaus; não conseguiram resistir à falta quase constante de energia elétrica, água e alimentação deficiente. Não havia mercados nos bairros, o único existente era o Mercado Municipal (Antônio Lisboa), que nós ainda conhecemos às margens do rio Negro, no centro da cidade, ao lado do porto. Para se comprar qualquer alimento perecível como, por exemplo, carne ou peixe, tinha-se que madrugar quase diariamente no Mercado Central, porque esses alimentos não podiam ser estocados congelados devido à falta de frigoríficos na cidade ou geladeiras elétricas nas residências, só havia a querosene, que funcionavam muito precariamente. $\mathrm{O}$ leite in natura era escasso e não muito confiável. O leite em pó também nem sempre se encontrava à venda nas mercearias. Os telefones nunca funcionaram a contento, especialmente quando se desejava telefonar para outras cidades. Por isso a maioria desses pesquisadores acabou desistindo de ficar em Manaus por longo tempo, especialmente os que tinham filhos pequenos, como o Dr. Jaccoud, por exemplo. Durante os dois primeiros anos, em Manaus, o INPA custeava inteiramente o aluguel de nossas residências. Recebíamos o salário integral, em compensação não tínhamos direito à previdência social quer pública ou privada nem a algum plano de saúde, muito menos a um seguro de vida ou outro direito qualquer. Se a instituição fechasse ou ficássemos doentes não tínhamos direito algum garantido. Isto perdurou até 1965, quando fomos enquadrados oficialmente como servidores públicos. Os solteiros, como eu, por exemplo, não tínhamos o mesmo problema. Nossas refeições e inclusive o café da manhã eram em geral feitos nos restaurantes que havia no centro da cidade como a Pensão Maranhense, o Restaurante Avenida, o Restaurante do Hotel Central etc. Nos fins da tarde, depois do expediente, nos reuníamos na esquina da Avenida Eduardo Ribeiro com a Sete de Setembro para um bate-papo descontraído, antes do jantar. Nos fins de semana, freqüentávamos, os alguns balneários que existiam no entorno da cidade, como, por exemplo, o do Prof. Guilherme Nery, na Chapada de Flores, ou do Dr. Moura Tapajós, no Parque Dez, para jogarmos futebol, nadar ou para um batepapo. À noite, por terem geradores próprios de luz, freqüentávamos o Ideal Clube ou, então, íamos a um cinema como o Cine Odeon, a melhor casa de diversões que existia na época, em Manaus. Levávamos um vida tranqüila, que nos fazia esquecer em parte o relativo conforto que as grandes cidades nos oferecia e mesmo a saudade dos nossos familiares e amigos, que deixamos no Rio. Levávamos uma vida de plena quietude, em particular nós, solteiros. Não nos incomodava se não havia luz ou água em casa ou se a comida era difícil de se conseguir. Do nosso ponto de vista, para tudo se dava um jeito. Nossas roupas, as lavadeiras cuidavam delas. Não faltava na cidade lavadeiras que se ocupavam desse mister com muito gosto e por necessidade.

Durante os primeiros anos após a fundação do INPA, por várias vezes ele esteve ameaçado de fechar as portas por falta de repasse de recursos e pelas dificuldades de recrutar novos pesquisadores para o seu quadro. Sempre que saia um diretor, pairava sempre a dúvida. Em 1964, o INPA sofreu uma série de ameaças, em especial, durante o início do período do Regime Militar. O CNPq estava sob ameaça de extinção e consequentemente o INPA seria afetado em cheio. A inquietação entre os servidores era geral, em particular, quando, pela primeira vez, deixamos de receber os salários por uns três meses. Fui para Manaus, em princípio, visando não só aplicar os meus conhecimentos adquiridos na banca escolar como uma grande

\footnotetext{
${ }^{1}$ A primeira universidade brasileira foi fundada em M anaus em 17/01/1909 sob o nome de Escola Universitária Livre de M anaus ou U niversidade de M anaus, segundo Aderson de Menezes (A primeira universidade brasileira - Reivindicação histórica. (Reedição). Manaus / AM . 2000.23 p), da qual só restaram a Faculdade de Ciências Jurídica e Sociais (hoje desmembrada em Faculdade de Direito do Amazonas e Escola de Serviços Sociais da U niversidade do Amazonas), a Escola Agronômica de Manaus (extinta em 1943) e a Faculdade de Farmácia e O dontologia (extinta em 1944).
} 


\section{ACTA \\ AMAZONICA}

ENTREVISTA: WILLIAM RODRIGUES oportunidade de crescer profissionalmente dentro de minha especialidade, visto que a flora amazônica sempre foi e ainda continua sendo um enorme paraíso para os botânicos de modo geral ainda muitíssimo pouco conhecido cientificamente. Poderia ter ficado no Rio, onde vivi a maior parte de minha juventude. No Rio, eu trabalhava no Ministério da Guerra (Diretoria de Engenharia), hoje Ministério do Exército [da Defesa] como servidor público de carreira (Escriturário, prestes a ser promovido para oficial administrativo), encarregado da tradução de manuais técnicos do Exército Americano. Ao ser convidado pelo Dr. Olympio da Fonseca, primeiro Diretor do INPA e meu exprofessor universitário, de Biologia, não titubeei Minha intenção não era ficar a vida toda trabalhando como burocrata, mas, gostaria de ir mais além, fazendo um curso superior (advogado, médico, ou outra profissão qualquer). No entanto, quis o destino que me formasse em História Natural e depois me especializasse em Botânica. Nunca fui muito ambicioso com recursos materiais, de forma que acabei abraçando de vez a profissão de pesquisador botânico e nunca mais a troquei por outra eventualmente mais rendosa ou que me desse maior status social.

\section{O que era o INPA naquele tempo?}

O INPA, quando cheguei, estava começando a se estruturar. Não tinha, obviamente, ainda nada montado para se começar uma pesquisa qualquer. Começamos da estaca zero. Na Botânica, para não dizer que não tínhamos nada, havia apenas um microscópio estereoscópico trazido pelo Dr. Jaccoud em mãos do Rio para dissecção de material e ajuda na identificação botânica do que fosse possível. Alguns outros pesquisadores, como eu, também, levamos todos os livros pessoais de que dispúnhamos para o nosso uso em Manaus. O Dr Jaccoud, conforme ele me confessou pessoalmente, foi o primeiro pesquisador contratado pelo INPA (maio ou junho de 1954) e um dos primeiros a chegar a Manaus na manhã de 27 de julho do mesmo ano. O Hospital da Santa Casa de Misericórdia, de Manaus, a Secretaria de Saúde do Amazonas, o Laboratório de Veterinária, do Departamento de Economia Agrícola do Estado do Amazonas, cederam seus laboratórios e equipamentos para o setor médico e de veterinária do INPA poderem iniciar provisoriamente os seus estudos. A Botânica, no momento de sua instalação era a que menos precisava de qualquer equipamento para os seus trabalhos iniciais, a não ser de um pequeno espaço para herborização. Ocupávamos uma saleta localizada nos fundos da sede provisória do INPA. Como não tínhamos estufa nem qualquer outro meio para secagem de plantas, utilizávamos, sempre, que possível, a luz solar. Havia uma auxiliar (Maria Helena Bacelar) contratada exclusivamente na época como auxiliar de laboratório, que cuidava dessa parte. Toda vez que ameaçava chover, ela recolhia imediatamente todo material espalhado pelo pátio do prédio. Durante a sua instalação, o INPA conseguiu, também, trazer do Rio três técnicos de laboratório, experientes, para a captura de insetos e outros serviços correlatos. A maioria dos auxiliares técnicos eram estudantes dos colégios locais (Colégio Estadual do Amazonas e Instituto de Educação), que depois tiveram de participar de um curso ministrado por toda a equipe de pesquisadores do INPA para trabalharem nos respectivos laboratórios em funcionamento na época. Alguns deles acabaram se destacando mais tarde como pesquisadores, quando tiveram oportunidade de cursar uma Universidade fora de Manaus, como bolsistas do INPA, já que não existia no Estado uma Universidade instalada ou em vias de implantação voltada para formar técnicos ou pesquisadores para o INPA. Essa medida foi a única saída encontrada mais tarde pela instituição, não só para estimular a formação do pessoal local como um jeito prático de preparar seu próprio pessoal especializado para atuar no Instituto, visto que trazer pesquisadores de fora era muito difícil, por várias razões, inclusive, baixos salários oferecidos, nada competitivos com os do Sul. Alguns professores ou pesquisadores radicados na região foram convidados, em 1955, a trabalhar no INPA, tais como o bioquímico Bastos Lira (formado em Farmácia e Odontologia pela Escola Universitária Livre de Manaus), o historiador e advogado Mário Ypiranga Monteiro, o Prof. advogado Afonso Nina, o advogado e físico Octávio Mourão e alguns médicos como o Dr. Djalma Batista, especialista em Patologia Clínica e Tisiologia, e alguns outros. Inicialmente, o INPA funcionou num pequeno prédio situado na Praça da Saudade, rua Simão Bolívar, 203, até dezembro de 1955, quando, então, mudou-se em parte para a rua Guilherme Moreira, 116, onde permaneceu até dezembro de 1972 e uma outra parte, inclusive a Botânica, passou para todo o $10^{\circ}$ andar do Edifício do IAPETC (Instituto de Aposentadoria e Pensão dos Empregados de Transportes e Cargas), hoje INSS, único edifício imponente, existente em Manaus na época, situado na Praça D. Pedro II, onde permaneceu até dezembro de 1971. Nesse prédio do IAPETC funcionou durante muito tempo o Centro de Pesquisas Florestais (CPF), pertencente, inicialmente à antiga SPVEA (Superintendência de Valorização da Amazônia), atual SUDAM, que, após o rompimento do convênio INPA/SPVEA, passou a constituir a $3^{\mathrm{a}}$ Divisão do INPA. Aí, ficava a Botânica, o Herbário e um alojamento para hospedagem de visitantes ou convidados do INPA.

Nos primeiros anos de implantação do INPA, ele esteve ameaçado várias vezes de ser extinto por falta constante de recursos financeiros, de boa equipe de pesquisadores e de um salário competitivo com que era oferecido no Sul do país. Éramos simples servidores, sem estabilidade funcional alguma, sem qualquer direito funcional e sem qualquer perspectiva de criação de uma carreira estável. Não contribuíamos para nenhum instituto de previdência. Em caso de algum acidente, invalidez ou morte não tínhamos oficialmente amparo algum. Essa situação perdurou até 1965 , quando foi oficializada a efetivação de todo o pessoal da entidade num Quadro Especial a contar de 01/10/ 1961, dando a partir daí estabilidade funcional a todos os seus servidores. A precária condição - de toda ordem da região, não constituía, também, atrativo algum para a fixação da maioria dos servidores vindos de fora, especialmente os que vinham com suas famílias. Transporte, só ônibus, e assim mesmo muito precário e frágil, como o ônibus apelidado de Zepelin. Bonde nem pensar, apesar de a cidade ser quase toda ela cortada por 
linhas de bonde, um dos poucos vestígios dos tempos fastigiosos da cidade. Os cachorros andavam em pleno centro da cidade, revirando latas de lixo à procura de comida e os urubus infestavam as principais vias públicas, atrás de carniça. Muitos poucos resistiram, como o entomólogo Nelson Cerqueira e eu, que era solteiro e punha toda a fé no futuro do INPA e na vinda, um dia, de dias melhores. Também, eu via no INPA uma chance enorme de poder progredir profissionalmente e de dar algo de mim pelo engrandecimento do INPA na Amazônia. Nunca tive dúvidas sobre isso. Nunca esmoreci.

\section{Como, por quê e para quê o INPA foi criado?}

O INPA foi criado como uma resposta do governo brasileiro, sob a presidência de Getúlio Vargas, às intenções de alguns organismos exteriores em internacionalizar toda a Hiléia. A sua criação ocorreu em 27/10/1952 pelo Decreto no 31.672 como um dos institutos do novel Conselho Nacional de Desenvolvimento Científico e Tecnológico-CNPq. A solenidade de sua instalação aconteceu no Salão Nobre da Associação Comercial do Amazonas com a presença de diversas autoridades, entre elas, do Vice-Almirante Álvaro Alberto, primeiro presidente do CNPq e do Dr. Olympio Oliveira Ribeiro da Fonseca Filho, primeiro diretor do INPA. O INPA foi fundado com o objetivo de promover o estudo científico do meio físico e das condições de vida da região amazônica, tendo em vista o bem-estar humano e os reclamos da cultura, da economia e da segurança nacional.

\section{Quais eram as pessoas envolvidas no seu processo de criação?}

O Vice-Almirante Álvaro Alberto, o Dr. Olympio da Fonseca Filho, o Prof. Arthur César Ferreira Reis, Dr. Paulo Carneiro (mesmo responsável pela proposta de criação do Instituto Internacional da Hiléia Amazônica), Sócrates Bonfim, Gastão Cruz e mais alguns outros, todos eles encarregados da elaboração do anteprojeto de criação do INPA.

\section{O que foi o Instituto Internacional da Hiléia?}

Era um organismo internacional criado pela UNESCO em 1948, cuja sede seria Manaus e se irradiaria por toda Amazônia sob o apoio financeiro e técnico desse organismo internacional. Com a criação do Instituto, os seus pesquisadores teriam livre circulação em todos países com território na região amazônica. Com a criação do Instituto Internacional da Hiléia, corríamos grande risco de perder o domínio soberano total da Hiléia, passando todo ela às mãos de países mais potentes, visto que o referido órgão teria irrestritos direitos de extraterritoriedade. Fariam parte do mesmo nove nações e sete entidades internacionais.

\section{Quem foi o botânico Adolfo Ducke? Que importância ele teve para a comunidade amazonense?}

O Dr. Adolfo Ducke foi um pesquisador contratado pelo Museu Goeldi para realizar pesquisas sobre abelhas sociais na Amazônia. Trabalhou muito tempo em colaboração com Jacques Huber, do qual recebeu tamanha influência que após a morte de seu tutelar, em 1914, acabou voltando-se inteiramente para os estudos botânicos, tornando-se, a partir daí num dos maiores especialistas da flora amazônica, que o Brasil já teve até hoje. Coletou por quase toda a Amazônia brasileira e descreveu mais de mil novas plantas amazônicos. Seu nome ficou, inclusive, eternizado em centenas de novas espécies, gêneros e particularmente, numa família, que tem o seu nome - Duckeodendraceae. Dedicou quase 50 anos de sua vida aos trabalhos de campo na Hiléia, isto entre 1900 até 1948. Foi o responsável direto pela criação da Reserva Florestal do INPA que acabou recebendo o seu nome. A escolha da sede do INPA em Manaus, também, deve-se ele, quando em um dos seus trabalhos ${ }^{2}$, ele manifestou de que a região central em que se encontra a capital do Amazonas representava uma síntese da flora e fauna amazônicas. Foi consultor do INPA até a sua morte ocorrida em Fortaleza, em 05/01/1959, aos 82 anos. Troquei com ele várias correspondências, já que no fim de sua vida, preferiu radicar-se em Fortaleza. Só me encontrei pessoalmente com ele duas vezes no Rio de Janeiro, uma no Hotel Serrador, onde hospedara-se e logo depois no Jardim Botânico, ocasião em que visitava com sua esposa, D. Josefina, o seu velho amigo, João Geraldo Kuhlmann, também exconselheiro do INPA, para a área de Botânica.

Ao final do Império existia em Manaus, no Caxangá (Hoje Manaus Moderna) o Museu Botânico. Quem fundou o Museu Botânico, quem o dirigiu e que importância ele teve para a comunidade amazonense?

O Museu Botânico de Manaus foi fundado em 1883, tendo como seu único diretor e administrador o naturalista João Barbosa Rodrigues. A região já era conhecida dele desde 1872, quando começou as suas primeiras pesquisas na Amazônia reunindo e classificando plantas e objetos indígenas como os muiraquitãs. Consta que a verdadeira fundadora do Museu Botânico foi a Princesa Isabel, de quem Barbosa Rodrigues contava com seu apoio e admiração. Barbosa Rodrigues, embora republicano, nunca deixou de ser apoiado pelo Governo Imperial. D. Pedro II, segundo consta, o admirava, também, tanto que muitas vezes esteve presente durante suas conferências. $\mathrm{O}$ Museu, infelizmente, teve vida efêmera. Sete anos depois (1889) Barbosa Rodrigues era destituído do cargo e o Museu extinto por ordem do governador do Amazonas, o Capitão Augusto Ximeno de Valleroy. O Museu chegou a ter sua própria revista

${ }^{2}$ A Amazônia Brasileira. Em Anais da Primeira Reunião Sul-Americana de Botânica, vol 1., p. 275-287 il. Rio de Janeiro. 1938. 
denominada Vellosia, que cessou de ser publicada no quarto volume. No último relatório da instituição, feito pelo seu genro, Campos Porto, e publicado na revista Vellosia, consta que Barbosa Rodrigues deixou, ao sair de Manaus, um herbário com 10.000 exsicatas e 1.260 objetos indígenas amazônicos diversos. Infelizmente, não se sabe até hoje o destino dessa preciosa coleção. Foi jogado fora ou, então, acabou se decompondo por falta de cuidado, o que não ocorreu com sua Biblioteca, que foi melhor conservada e transferida para o Colégio Estadual do Amazonas. O acervo dessa Biblioteca era de grande valor científico. Contava com obras raras como a Flora brasiliensis de Martius, Viagem de D'Orbigny, as coletâneas de Linnaea, Buffon, Adansonia, Castenaux, Prodromus de Candolle e outras obras clássicas mais de interesse para o estudo da flora amazônica. Esse precioso acervo encontra-se, hoje, no INPA. Na lombada de alguns livros encadernados ainda se pode ver o nome da instituição impresso com o título nominativo "MUSEU".

\section{Que contribuição teve Barbosa Rodrigues para a criação e fundação do Instituto?}

A grande contribuição indireta que eventualmente Barbosa Rodrigues teve durante a fundação do INPA foi ter deixado uma valiosa coleção bibliográfica arquivada no Colégio Estadual do Amazonas, que em convênio com o INPA passou a integrar as primeiras coleções importantes do acervo bibliográfico do INPA.

Convém, também, destacar. que de toda coleção botânica feita por Barbosa Rodrigues na Amazônia, nada restou, conforme já mencionado anteriormente, exceto um espécime-tipo de Tynanthus ignei Barb. Rodr.(sinônimo de Pyrostegia cinerea Bureau, Bignoniaceae), deixado, ocasionalmente, dentro de um livro da revista francesa Adansonia. Esse exemplar constitui, hoje, uma amostra raríssima de suas coleções, depositada, hoje, como uma preciosidade no Herbário do INPA. Essa descoberta foi comunicada por mim, em 1980, durante o XXXI Congresso Nacional de Botânica, realizado em Ilhéus, BA.

Barbosa Rodrigues era um naturalista eclético, de vasta cultura, destacando-se, no entanto, na Botânica como orquidófilo e especialista em Palmeiras. Escreveu várias obras, não só sobre orquídeas e palmeiras, mas também, sobre antropologia, geologia e geografia com diversas descrições de costumes e objetos indígenas. Dentre suas obras clássicas convém destacar o Sertum Palmarum Brasiliensium (1872/1875), em 2 volumes, onde descreve e ilustra em aquarela inúmeras palmeiras da flora brasileira, a maioria estudada ou descoberta por ele próprio e a obra Orquídeas do Brasil, (1869/1872), em 17 volumes.

\section{Quais foram as primeiras pesquisas produ- zidas pelo INPA?}

A primeira pesquisa do INPA foi no campo da Geomorfologia, executada sob a direção do francês, visitante do INPA, Prof. Francis Ruellan, Diretor da Escola de Altos Estudos de Paris nos campos de Roraima. Foram feitas duas expedições em dois anos seguidos, uma em 1954 e a outra em 1955. Esses estudos tiveram a participação de diversos pesquisadores convidados e a presença de vários estudantes de Manaus de um curso que vinha sendo ministrado pelo Prof. Ruellan e sua equipe, no INPA. Os resultados dessa pesquisa foram publicados em alguns trabalhos, entre eles o intitulado Expedições geomorfológicas no Território do Rio Branco, publicado pelo INPA.

Uma outra importante expedição geológicopaleontológica americano-brasileira ocorreu em 1956 no Alto rio Juruá, chefiada pelo Dr. Llwellyn I. Price, do Departamento Nacional de Produção Mineral, que resultou na publicação avulsa do INPA no. 5, intitulada Uma expedição geológica e zoológica no Alto rio Juruá, Território Federal do Acre, realizado sob os auspícios do Instituto Nacional de Pesquisas da Amazônia em 1956.

Além das publicações acima, algumas outras foram escritas por pesquisadores do INPA, pouco tempo depois, resultantes de estudos incentivados pelo $1^{\circ}$ diretor do INPA, o Dr. Olympio da Fonseca ${ }^{3}$. Em janeiro de 1955, o INPA esteve presente pela $1^{\mathrm{a}}$ vez no VI Encontro Anual da Sociedade Botânica do Brasil, realizado em Belém, onde eu e o Dr. Karl Arens fizemos pessoalmente a apresentação do estudo farmacológico de Pluchea suaveolens (Vell.) O. Kuntze, trabalho esse em co-autoria com K. Arens e R. J. S. Jaccoud e W. A. Rodrigues; a histometria quantitativa de madeira, apresentado por K. Arens; e da anatomia da semente de guaraná Paullinia cupana var. sorbilis (Mart.)Ducke, apresentado por K. Arens.

\section{Quando aconteceram as primeiras expe- dições do INPA e para onde?}

Em fins de 1954, conforme já mencionado anteriormente, ocorreu a primeira grande expedição Geomorfológica ao Território Federal de Roraima, hoje Estado de Roraima, dirigida pelo Prof. Francis Ruellan, Diretor da Escola de Altos Estudos de Paris e sua equipe. Dessa expedição participei como chefe do Grupo Norte, quando tive oportunidade de coletar exsicatas para o Herbário e amostras de rocha dos solos da região percorrida 
por mim. Dessa expedição e de uma segunda, realizada no ano seguinte, resultaram na publicação de alguns trabalhos, entre esses o intitulado Expedições geomorfológicas no Território do Rio Branco e uma tese de doutorado.

\section{O que representou a expedição aos campos de Roraima para você?}

Foi meu debute como botânico. Nunca havia participado de uma expedição científica, nem montado num cavalo, muito menos chefiado um grupo de pesquisa no campo e puxado uma tropa de bois. Foi para mim um batismo inesquecível e um tanto embaraçoso, visto que eu não tinha ainda experiência alguma de campo e muito menos contava com alguém mais experiente que eu numa expedição desse tipo. A preparação e secagem do material botânico colhido no campo era muito difícil porque não levava comigo nada para preparação das plantas colhidas senão jornais e uma prensa e nada mais. A secagem era feita à luz do sol, sobre o dorso dos animais, que transportavam nossa bagagem de campo, material coletado (plantas secas, amostras de pedras etc), por isso as minhas primeiras coletas botânicas na Amazônia foram da pior qualidade Acompanhou-me nessa excursão, além dos tropeiros contratados, o fotógrafo, Lourival Salgado, responsável pela documentação fotográfica das regiões percorridas, o Sr. Joaquim Chagas como mateiro e auxiliar de campo, o Sr. Firmino, como cozinheiro e caçador, e o Sr. José Gouveia, nosso guia de campo.

\section{Quando ocorreu a primeira expedição exclusivamente organizada pelo INPA?}

Em fins de 1956, ocorreu a primeira expedição multidisciplinar organizada exclusivamente pelo INPA aos rios Uatumã e Uburu, sob a chefia do Dr. Raul Antony. Essa expedição foi relatada por mim e publicada no Boletim Geográfico ${ }^{4}$.

\section{O Sr. esteve presente no momento da criação do INPA?}

Infelizmente, não. Nessa ocasião, eu estava estagiando no Museu Nacional do Rio de Janeiro, por indicação do Dr. Olympio da Fonseca, para trabalhar no INPA.

\section{Quais foram as fases difíceis da Botânica?}

O real fundador da Botânica e de seu herbário foi o Dr. Olympio da Fonseca, $1^{\circ}$ Diretor do INPA, quando propôs o $1^{\mathrm{a}}$ organograma do INPA, constituído de seis Divisões. Nessa estrutura provisória, a Botânica fazia parte da $3^{\text {a }}$ Divisão e deveria funcionar da seguinte forma: Botânica Geral, Botânica Criptogâmica, Botânica Fanerogâmica juntamente com a
Zoologia Geral, Zoologia dos Invertebrados, Zoologia dos Vertebrados, Microbiologia Geral e Industrial, Limnologia, Citologia e Genética, Ecologia. Infelizmente, essa estrutura era irreal para a região, tanto que mais tarde, o Prof. Arthur Reis, como diretor do INPA, foi obrigado a refazê-la, colocando a administração científica do INPA dentro da realidade presente na época, reduzindo as seis pretensas Divisões em apenas duas e aí situar todo o pessoal técnico-científico.

Ao Dr Jaccoud, no início, e a mim, em particular, competiu-nos levar a diante os objetivos do Dr. Olympio. Em meados de 1955, o farmacêutico Ernani Ferreira foi admitido como botânico, porém sua permanência no INPA durou passageira. Ele se demitiu na época em que houve uma debandada quase geral de pesquisadores do Centro de Pesquisas Florestais, como dos agrônomos Roberto Onety Soares, Anderson Soares, Rubem Valle, do engenheiro Robert Lechthaler, técnico de celulose e papel, e alguns outros que preferiram deixar o INPA à procura de melhores condições de trabalho, fora de Manaus, visto que pairava no Centro de Pesquisas Florestais, em 1959, uma grande crise. Esse setor deixou de receber recursos do convênio SPVEA/INPA e a direção do INPA se viu obrigada a adotar um programa de severa compressão de despesas, só possível por meio de dispensa de pessoal e redução de atividades de toda ordem. O Dr. Jaccoud ficou no INPA até o fim de 1955. Com a saída desse pessoal, durante muitos anos, passei a ser o único botânico a permanecer na instituição até me aposentar em 1991. Nesse ínterim, a Dra. Marlene Freitas da Silva, que já vinha trabalhando comigo desde 1955, como técnica, formouse em Bioquímica e Farmácia pela Universidade do Amazonas e posteriormente fez o mestrado e doutoramento no INPA e o Dr.Byron Wilson Pereira de Albuquerque, também se formou em Biologia, no Rio de Janeiro, e posteriormente obteve o título de Mestrado no INPA.

Em 1956, durante a direção do Dr. Tito Arcoverde, a Botânica esteve prestes a se extinguir, quando fiquei afastado do INPA para reassumir minhas funções no Ministério da Guerra, no Rio, aguardando a chamada do Dr. Tito para poder voltar para Manaus, agora como licenciado, sem vencimento, do Ministério da Guerra. O INPA era uma instituição em fase experimental, que poderia fechar a qualquer momento ou ser transferida para algum outro órgão. Dessa forma, por motivo de precaução, fui me segurando no Ministério até quanto possível. Nesse ínterim, a Botânica era um dos setores mais ameaçados do INPA, especialmente, pelo rompimento do convênio com a SPVEA. Felizmente, não fechou, entre outras coisas, porque decidi voltar para o INPA, com o sinal verde dado pelo Dr. Tito e porque o CNPq fez tudo que fosse possível para manter a instituição funcionando. Na dúvida, se eu voltaria ou não, o Dr. Tito já estava transferindo toda a nossa coleção de exsicatas para o Museu Goeldi,com o intuito de fechar o setor porque a Botânica não podia se manter sem um botânico para justificar a sua existência. Convém destacar, ainda, que a

${ }^{4}$ Rodrigues, W. a 1960. Relatório preliminar da viagem de reconhecimento pelos rios U atumã e U rubu.

Boletim Geográfico, 159: 1045-1072. 
seção de Botânica, não fechou, felizmente, porque, ao reassumir minhas funções, fui consultado pelo Dr. Tito se eu não gostaria de me transferir para o Museu Goeldi, em Belém. Prontamente, lhe respondi que meu desejo era continuar em Manaus, visto que essa cidade oferecia melhores condições de trabalho no campo para um botânico do que em Belém, além do mais, que eu, particularmente, gostava muito mais de Manaus do que de qualquer outra cidade, assim não gostaria de trocar essa cidade por qualquer outra.

Outra feita, também, numa de minhas idas ao Rio a serviço, o Dr. José Cândido, ex-Diretor do Museu Goeldi e então Diretor do Museu Nacional do Rio de Janeiro, quis contratar-me para trabalhar no Museu, oferecendo-me, também, a chefia da Botânica. Mais uma vez tive de declinar-me do honroso convite.

\section{Quais foram às fases mais difíceis vividas pelo INPA?}

O INPA como um todo, desde o início, passou por várias crises financeiras e se ressentiu de bons pesquisadores. A pior fase ocorreu, em 1964, durante o Regime Militar, quando todos os servidores do INPA deixaram de receber o salário durante três meses e se cogitava no Governo de se extinguir o INPA ou transferi-lo para outro órgão. Creio que por interferência, em particular, do Dr. Djalma Batista, na ocasião, Diretor do INPA, e o bom senso das autoridades em Brasília de dar melhor solução ao caso, resolveram estabelecer novas diretrizes ao INPA para tentar salvá-lo.

\section{Você assumiu a direção do INPA por três meses, em substituição a Djalma Batista, então, diretor?}

Nunca cheguei a ser Diretor titular do INPA, apenas diretor substituto por várias vezes, desde 1963, a partir da gestão do Dr. Djalma Batista, até perto de me aposentar, em 1991. O maior período em que ocupei a direção do INPA, foi logo após o início do regime militar instituído no país, em 1964 , quando o Dr. Djalma teve que se ausentar de Manaus a chamado do CNPq, em Brasília. Nessa ocasião, eu me encontrava no Rio, gozando do ano sabático, quando o Dr.Djalma me chamou para ficar em seu lugar na direção do INPA. Ocupei, também, na instituição, vários cargos de chefia: Chefe do Centro de Pesquisas Florestais (CPF), Diretor da $3^{\text {a }}$ Divisão, Chefe da Botânica, Diretor da Área de Pesquisa do INPA e, por fim, Diretor de Ciências Biológicas.

\section{Tem algum fato importante que mereça destaque?}

Fiz muitas excursões pela Amazônia. Em cada uma sempre existe um ou mais fatos que, eventualmente, dariam um livro. Nos meus trabalhos de campo, experimentei quase tudo que era transporte, tanto aéreo como fluvial: canoas, barcos, hidroavião da FAB e particular, teco-teco, helicóptero etc. Passei algumas vezes por maus momentos, porém, graças a Deus, ainda continuo vivo. Fui ameaçado por índios, escapei por milagre de mais de um desastre de avião, estive perdido na mata, senti o desconforto de longas dormidas em plena mata com ou sem chuva, com ou sem carapanãs, piuns, mucuins, carrapatos etc, senti o desconforto de uma malária, felizmente benigna. Por várias vezes estive ameaçado de naufrágios, cachoeiras ou corredeiras, senti intoxicação alimentar em plena mata distante de qualquer recurso médico, escapei várias vezes de ser atingido por queda de árvores em plena mata, escapei de ser picado por cobras venenosas etc. Esses fatos, infelizmente, fazem parte de nossa profissão, quando em excursão pelo hinterland amazônico.

No meado de 1965, recebi em Manaus o Rei Leopoldo III, da Bélgica, acompanhado de um ictiólogo e do Dr. Murça Pires, designado pelo Governo para acompanhá-lo em sua viagem pelo Amazonas para pescar e realizar alguns estudos sobre a fauna aquática amazônica. Como grande amigo do Dr. Murça, prestei a Sua Majestade toda a atenção que merecia, em Manaus. Como ele vinha ao Amazonas em caráter particular, ninguém soube de sua passagem pela cidade, nem a imprensa. Na época eu possuía um carrinho particular da marca Standard, já velho, que vivia enguiçando. Além disso, era desconfortável para uma pessoa alta como ele. Mesmo assim o Rei Gustavo preferiu andar no meu desconfortável carro do que alugar um outro para fazer os preparativos para a viagem e visitar alguns pontos turísticos. Algumas vezes o carro enguiçava e como a bateria estava fraca, o jeito era empurrá-lo para voltar a funcionar. O Rei Gustavo demonstrava que era uma pessoa simples, apesar de posição monárquica. Quando o carro enguiçava, ele, que viajava sempre ao meu lado, desconfortavelmente na frente pelo tamanho de suas pernas, era o que prontamente se oferecia para empurrar o meu carro. Deste modo, hoje tenho o orgulho de dizer que na minha vida, uma vez um rei foi meu vassalo.

Outra feita, quando excursionava pelo alto rio Uraricoera, Roraima, com o Murça e Guido Ranzani e alguns auxiliares, quando paramos no fim da tarde numa clareira para montar o nosso acampamento nas margens secas do rio. No local, estavam acampados também uns índios Ianomami com algumas mulheres indígenas. Ao nos prepararmos para fazer o acampamento, os índios Maiongong, que nos serviam de práticos de rio, ouviram uma conversa dos índios acampados que iriam tomar nossas canoas de qualquer jeito para prosseguirem viagem com as mulheres. Ao tomarmos conhecimento das pretensões deles, tivemos de levantar acampamento e pegar de novo imediatamente as nossas canoas e sairmos do local para outro onde eles não nos poderiam alcançar. Como já estava ficando bem escuro, tivemos que parar num mata alagada (igapó) e aí instalarmos nossas redes nos troncos das árvores, acima do nível das águas, e dormirmos até amanhecer. Felizmente, nada aconteceu de mais grave durante a noite, como, por exemplo, quebrar um galho ou uma cobra qualquer nos dar um susto. 
Afora os fatos casuais acima mencionados, convém destacar que a vinda do Dr. Ghillean T. Prance, do Jardim Botânico de Nova Iorque, a partir de 1966, para fazer excursões botânicas pela Amazônia em colaboração conosco, representou uma fase de grande desenvolvimento para a Botânica do INPA e, em especial, para o herbário. Nossas coleções cresceram consideravelmente com suas coletas. Em 1973, por sugestão dele e grande dinamismo do Dr. Paulo de Almeida Machado, ex-Diretor do INPA, foi criado o curso de Botânica Tropical, em nível de pós-graduação (mestrado), destinado a formar botânicos altamente qualificados. Grandes mestres mundiais da Botânica estiveram no INPA ministrando cursos. O curso de Mestrado iniciou com quatro botânicos do INPA, três da Universidade Federal do Pará, dois da Universidade Federal do Amazonas e dois da Universidade Federal de Mato Grosso.

Durante o período de 1967-1969, especialmente, foi muito importante, também, para a Botânica. Além de continuação dos estudos florísticos e descoberta de novos táxons para a ciência, seus pesquisadores realizaram estudos de ecologia, fitossociologia e fitogeografia da Amazônia. Destacam-se os trabalhos feitos sobre ciclo biogeoquímico da serrapilheira de uma floresta da Amazônia Central feitos em colaboração com o Instituto Max-Planck de Limnologia da Alemanha e alguns estudos sobre a biomassa da floresta de terra firme da Amazônia Central.

O auge da Botânica ocorreu entre 1977 a 1987, com a criação do Projeto Flora Amazônica e efetuação de grandes expedições binacionais por quase toda Hiléia com o apoio financeiro da Fundação Nacional de Ciências dos Estados Unidos (NSF) e do CNPq e participação do INPA e do Museu Goeldi, pelo lado brasileiro, e do Jardim Botânico de Nova Iorque, pelo lado americano. Foi uma fase de grande progresso nas pesquisas botânicas no Brasil, com vastíssimas coletas, inclusive, em lugares os mais distantes e os mais inacessíveis possíveis. Ainda hoje, toda a coleção feita durante todos esses 10 anos de muitas excursões ainda não se encontra totalmente estudada e do que já foi devidamente identificada taxonomicamente, tem dado resultados surpreendentes, em especial, com a descoberta de novos táxons e/ou de inúmeras plantas raras ou pouco conhecidas.

\section{Quando surgiu a Reserva Ducke (qual ano, onde ficava localizada, como foi cria- da e com qual finalidade)?}

A idéia de criação de uma Reserva Florestal já era um anseio do Dr. Adolfo Ducke, que nas suas pesquisas no entorno de Manaus, ficou tão entusiasmado com a biodiversidade das matas de Manaus, que resolver recomendar a preservação florestal de uma nesga dessa região, cuja cobertura vegetal, segundo ele, era bastante representativa da floresta amazônica central. Infelizmente, a área mapeada por ele, já estava quase toda tomada por posseiros quando o INPA resolveu solicitar do Estado a doação da gleba em questão como uma reserva biológica permanente.
O jeito foi escolher outra área adjacente, mais a leste, onde a floresta estivesse menos mexida ou em melhores condições de preservação. A área preservada ocupa hoje um espaço de pouco mais de $100 \mathrm{~km} 2$ e se encontra presentemente na periferia de Manaus, podendo considerar-se, presentemente, como um grande fragmento florestal urbano, não inteiramente descontinuado da floresta natural, ainda existente em grande parte do seu entorno. A Reserva Ducke foi doada ao INPA pelo Governo do Estado do Amazonas em 28 de novembro de 1962, pela Lei no 41, publicada no Diário Oficial de 16 de fevereiro de 1963, na gestão do Dr. Djalma Batista, embora em 22 de abril de 1958 o Prof. Arthur César Ferreira Reis tivesse expedido ordem de serviço para início da demarcação das terras, que deveriam pertencer à Reserva Ducke. Devido ao seu fácil acesso e proximidades de Manaus, inúmeras pesquisas já foram realizadas em sua área, incluindo coletas botânicas, inventários florísticos, experimentos silviculturais, fenológicos, ecológicas etc. Hoje, é uma das unidades de conservação melhor estudadas dentre todas as biotas preservadas no Brasil. Sobre sua flórula, já existe publicado, inclusive, o Guia de Identificação das Plantas Vasculares de uma Floresta de Terra Firme na Amazônia Central, elaborado por intermédio do convênio Internacional de Cooperação Técnico-Científica INPA/Reino Unido (Departamento para Desenvolvimento Internacional - DFID).

A Reserva Ducke foi uma das áreas melhor estudadas e coletadas por mim e meus auxiliares durante muitos anos. Fiz muitas coletas lá, descobri várias espécies novas ou pouco conhecidas, publiquei alguns trabalhos sobre sua flórula e cheguei a fazer, em 1963, o inventário 100\%, de uma área de 36 hectares contínuos de sua mata de terra firme, abrangendo 4616 árvores acima de $10 \mathrm{~cm}$ de diâmetro à altura do peito (DAP), devidamente demarcadas e numeradas com plaquetas de alumínio, visando não só fazer estudo taxonômico, biológico e ecológico mais minucioso das plantas demarcadas como, também, a elaboração futura de uma flórula da Reserva, que acabou se concretizando, quando o INPA, em 1987, conseguiu estabelecer um convênio com o Reino Unido para elaboração desse estudo, que acabou redundando em 1999, na publicação inicial da riquíssima e bem ilustrada obra já mencionada.

Assim, portanto, a idéia de se fazer uma publicação da flora da Reserva Ducke foi uma iniciativa nossa, posteriormente reiterada por nós, o Dr. Ghillean Prance e a Dra. Marlene Freitas da Silva.

\section{A CRIAÇÃO DA RESERVA WALTER EGLER}

No segundo semestre de 1965, realizamos ao longo da recém-aberta estrada Manaus-Itacoatiara, um extenso inventário florestal de $137 \mathrm{~km} 2$, desde o $\mathrm{km} 64$ até o km 260 , incluindo todos os tipos de vegetação existentes na área como todas as árvores de diâmetro acima de $25 \mathrm{~cm}$. Esse trabalho foi publicado parcialmente no volume $7 \mathrm{da}$ Biota Amazônica em 1967. 


\section{ACTA AMAZONICA}

ENTREVISTA: WILLIAM RODRIGUES
Antes desse estudo, já havíamos demarcado uma área de mata primária de 750 hectares, tendo $1,5 \mathrm{~km}$ de frente e $5 \mathrm{~km}$ de fundos como uma Reserva Biológica, que denominamos de Walter Egler, em homenagem a esse botânico, ex-diretor do Museu Goeldi, falecido tragicamente numa queda de cachoeira no alto rio Jari, rio divisório entre o Pará e o Amapá. A criação simbólica da referida Reserva se deu em fins de janeiro de 1963, durante a realização, em Manaus, do XIV Reunião da Sociedade Botânica do Brasil, da qual fui presidente, com a presença do Dr. Djalma Batista, Diretor do INPA, e dos congressistas. Nesse próprio do INPA, algumas pesquisas botânicas têm sido realizadas por nós como o estudo do ciclo biogeoquímico de sua floresta, estudo sobre biomassa etc., todos eles já publicados. As terras destinadas à formação da Reserva Biológica Walter Egler foram formalmente doadas ao INPA em 3 de outubro de 1968 pelo Governo do Amazonas, pela Lei no $780^{5}$

\section{E o serpentário? Tinha alguma ligação com a Reserva? Qual era a sua finalidade?}

Nos primeiros tempos do INPA, dispúnhamos de um pequeno serpentário improvisado instalado numa das dependências do prédio da rua Guilherme Moreira, sede do INPA. O responsável por esse serpentário era o Prof. Afonso Nina. As cobras venenosas eram mantidas dentro de algumas gaiolas, que o Prof. Nina criava para extração da peçonha, que, após desidratada, era enviada para o Instituto Butantã, em São Paulo. A criação desses animais dentro do prédio onde funcionavam alguns outros laboratórios e a Administração Geral, era extremamente perigosa. Embora raramente tenha ocorrido, ás vezes algumas dessas cobras escapavam do cativeiro e botavam todo os funcionários em pavorosa. Assim, surgiu-me a idéia, em 1964, quando estive temporariamente na direção do INPA, de propor a criação de um serpentário natural em plena floresta, na Reserva Ducke, dentro das condições ecológicas melhores possíveis, para criação de algumas cobras venenosas nativas da região, extração de veneno e produção futura de soro antiofídico para atender às necessidades regionais desse precioso medicamento terapêutico. Para tanto, eu contava com o Prof. Afonso Nina, ofidiologista, e do preparador de zoologia, Sr. Mozart Melo, que se encarregariam de cuidar do serpentário. Infelizmente, parece-me que houve alguma oposição dessa idéia dentro do $\mathrm{CNPq}$, de forma que esse plano não pôde ir avante. Segundo meu conhecimento, esse trabalho acabou sendo desenvolvido pelo finado biólogo Paulo Buhrnheim, que trabalhava no Instituto de Medicina Tropical do Amazonas, na área de ofidismo, e acabou criando na referida entidade uma Gerência de Animais Peçonhentos, com a finalidade de pesquisar e produzir venenos das cobras regionais, além de outros animais peçonhentos. Paulo Buhenheim acabou criando em 1999, posteriormente, no Município de Novo Airão, um serpentário conhecido por "Refúgio Arambóia", hoje dirigido por sua filha, também bióloga, Cristina Motta, dentro mais ou menos dos mesmos princípios idealizados por mim para o INPA, em 1964. 